\title{
UPAYA PEMELIHARAAN TEKANAN DARAH BAGI PASIEN HIPERTENSI DI RSUD SYEKH YUSUF KABUPATEN GOWA
}

\author{
Baharuddin K, Wirmawanti
}

Jurusan Keperawatan Poltekkes Kemenkes Makassaar

\begin{abstract}
ABSTRAK
Hipertensi dapat didefenisikan sebagai tekanan darah pasien persisten dimana tekanan sistoliknya diatas $140 \mathrm{mmHg}$ dan tekanan diastolik diatas $90 \mathrm{mmHg}$. Tujuan penelitan ini untuk mengetahui upaya pasien dalam mengontrol tekanan darah pada pasien hipertensi dengan mengontrol tekanan darah, diet hipertensi, berolahraga, dan keteraturan berobat. Penelitian ini dilakukan dengan metode deskriptif analisis, populasi yang diteliti adalah pasien hipertensi yang rawat inap di RSUD Syekh Yusuf Kabupaten Gowa. Teknik pengumpulan data yang digunakan adalah teknik Purposive sampling dengan jumlah responden sebanyak 65 orang. Instrumen pengumpulan data menggunakan lembar kuisioner dengan penilaian skala Gutman. Analisa data menggunakan analisa distribusi frekuensi kemudian disajikan dalam tabel. Hasil penelitian menunjukkan bahwa gambaran upaya pasien dalam mengontrol tekanan darah pada pasien hipertensi dengan mengontrol tekanan darah, diet hipertensi, berolahraga, dan keteraturan berobat masih sangat kurang. Hasil penelitian tentang upaya pasien dalam memelihara tekanan darah pada pasien hipertensi yaitu yang mengontrol tekanan darahnya 6 orang $(9,2 \%)$, tidak mengontrol tekanan darah 59 orang $(90,8 \%)$. Pengetahuan tentang diet hipertensi yang baik 8 orang $(12,3 \%)$, yang masih kurang 57 orang $(87,7 \%)$. Pengetahuan tentang Berolahraga yang baik 6 orang $(9,2 \%)$, yang berpengetahuan kurang 59 orang $(90,8 \%)$. Dan upaya berobat secara teratur 4 orang $(6,1 \%)$, yang berobat secara tidak teratur 61 orang $(93,9 \%)$. Kesimpulan dalam penelitian ini adalah masih kurangnya kesadaran pasien hipertensi dalam mengontrol tekanan darahnya menyebabkan masih tingginya kasus hipertensi dan komplikasi penyakit akibat hipertensi di RSUD Syekh Yusuf Kabupaten Gowa.
\end{abstract}

Kata kunci : Hipertensi, Tekanan darah

\section{A. PENDAHULUAN}

Menurut Health Survei for England 2002 yang dilakukan oleh Departemen Kesehatan persentase pasien hipertensi pada usia 16-24 tahun memang masih kecil yaitu antara $10-20 \%$. Persentase hipertensi tinggi pada usia di atas 75 tahun yaitu antara $70-80 \%$. Namun semakin bertambah usia, persentase penyakit hipertensi cenderung mengalami peningkatan. Pasien hipertensi di dunia saat ini diperkirakan mencapai lebih dari 800 juta orang. Sebanyak $10-30 \%$ di antara populasi orang dewasa pada hampir semua Negara terpapar hipertensi. Dari jumlah tersebut $50-60 \%$ penduduk saat ini, dapat dikategorikan sebagai mayoritas utama yang status kesehatannya akan menjadi lebih baik bila dapat mengontrol tekanan darahnya. Hipertensi sebagai penyakit paling dominan menyerang manusia di masa mendatang sudah mulai terdeteksi. Banyak faktor yang bisa mengarah kepada munculnya hiptertensi, diantaranya kurang control kesehatan dan pengaruh lingkungan. Faktor dominan yang paling masuk akal saat ini adalah kegemukan. Bila seseorang memiliki tekanan darah sistolik dan diastolic $\leq 140 / 90 \mathrm{mmHg}$, sudah berarti terkena hipertensi. Meskipun tekanan darah seseorang masih dalam batas normal tersebut namun tidak secara otomatis terbebas dari kemungkinan terkena hipertensi. Tetap dianggap berpotensi terkena hipertensi jika ditemukan beberapa faktor risiko diantaranya mengalami kegemukan, kolesterol dalam darah melebihi dari normal dan tidak mengontrol kesehatannya. Pada kelompok ini tetap perlu diberikan pengobatan untuk mengatasi hipertensi. Dampak penyakit ini pun tidak main-main. Biaya pemeliharaan kesehatan bisa membesar karena hipertensi sangat besar faktornya sebagai pemicu utama stroke, serangan jantung, gagal jantung dan gagal ginjal. Data hingga April 2006 jumlah pasien ginjal di Indonesia mencapai 150.ribu orang sementara yang tetap membutuhkan terapi agar ginjalnya tetap berfungsi sebanyak 300 ribu orang. Penyebab hipertensi 90-95\% tidak diketahui, menurut Pudji. Menurutnya 5-10\% hipertensi disebabkan karena penyakit lain seperti gangguan ginjal serta gangguan pembuluh darah.

Menurut World Health Organization (WHO), sekitar $30 \%$ penduduk dunia tidak terdiagnosa adanya hipertensi (Underdiagnosed Condition). Hal ini disebabkan tidak adanya gejala yang pasti bagi pasien hipertensi. Padahal hipertensi jelas merusak organ tubuh seperti jantung $(70 \%$ pasien heipertensi akan mengalami kerusakan jantung), ginjal, otak, mata, serta organ tubuh lainnya. Hal inilah yang menyebabkan hipertensi mendapat stigma sebagai pembunuh yang tidak terlihat atau Sillent Killer. (Susilo \& Wulandari, 2011).

Berdasarkan riset kesehatan dasar Depkes (Riskesdas) 2007, sekitar 76\% kasus hipertensi di 
masyarakat belum terdiagnosis. Hal ini terlihat dari hasil pengukuran tekanan darah pada usia 18 tahun keatas ditemukan prevalensi hipertensi di Indonesia sebesar 31,7\%. Yang mengerikan lagi, dari $31,7 \%$ prevalensi hipertensi tersebut diketahui, yang sudah mengetahui memiliki tekanan darah tinggi (hipertensi) berdasarkan diagnosis 7,2\%. Sementara dari kasus tersebut yang sadar dan menjalani pengobatan hipertensi hanya $0,4 \%$. Karena itulah, demi menyadarkan masyarakat akan pentingnya bahaya hipertensi, Indonesian Society of Hypertension (InaSH) terus berusaha mengampanyekan pentingnya menjaga kesehatan. (Okezone Online, 2013)

Penyakit tidak menular, terutama hipertensi terjadi penurunan dari 31,7 persen tahun 2007 menjadi 25,8 persen tahun 2013. Asumsi terjadi penurunan bisa bermacam-macam mulai dari alat pengukur tensi yang berbeda sampai pada kemungkinan masyarakat sudah mulai datang berobat ke fasilitas kesehatan. Terjadi peningkatan prevalensi hipertensi berdasarkan wawancara (apakah pernah didiagnosis nakes dan minum obat hipertensi) dari 7,6 persen tahun 2007 menjadi 9,5 persen tahun 2013. Hal yang sama untuk stroke berdasarkan wawancara juga meningkat dari 8,3 per1000 (2007) menjadi 12,1 per1000 (2013). Demikian juga untuk Diabetes melitus yang berdasarkan wawancara juga terjadi peningkatan dari 1,1 persen (2007) menjadi 2,1 persen, Riset Kesehatan Dasar Depkes (Riskesdas, 2013)

Prevalensi hipertensi di Indonesia yang didapat melalui pengukuran pada umur $\geq 18$ tahun sebesar 25,8 persen, tertinggi di Bangka Belitung (30,9\%), diikuti Kalimantan Selatan (30,8\%), Kalimantan Timur $(29,6 \%)$ dan Jawa Barat $(29,4 \%)$. Prevalensi hipertensi di Indonesia yang didapat melalui kuesioner terdiagnosis tenaga kesehatan sebesar 9,4 persen, yang didiagnosis tenaga kesehatan atau sedang minum obat sebesar 9,5 persen. Jadi, ada 0,1 persen yang minum obat sendiri. Responden yang mempunyai tekanan darah normal tetapi sedang minum obat hipertensi sebesar 0.7 persen. Jadi prevalensi hipertensi di Indonesia sebesar 26,5 persen $(25,8 \%+0,7 \%)$.

Hipertensi patut mendapat perhatian, karena di Amerika penyakit tersebut telah menjadi keprihatinan tersendiri. Mengingat, saat ini ada sekitar $20 \%$ penduduk Amerika atau lebih dari 50 juta orang yang terkena hipertensi. Setiap tahun ada sekitar 2 juta orang di Amerika terdeteksi kena hipertensi. Dari 50 juta populasi hipertensi, yang melakukan kontrol rutin hanya sekitar $27 \%$ dan sekitar $13 \%$ tidak mengetahui kalau mereka menderita (http://naturindonesia.com,2013)
Berdasarkan data RSUD Syekh Yusuf Gowa mulai dari Januari sampai Desember 2010 jumlah pasien Hipertensi sebanyak 229 orang dan mulai Januari sampai Desember 2011 jumlah pasien Hipertensi sebanyak 392 orang sedangkan jumlah pasien Hipertensi sejak Januari sampai Desember 2012 sebanyak 233 orang dengan jumlah kunjungan yang berfluktuasi dan cenderung meningkat dari bulan kebulan (Medical Record,2013).

Melihat jumlah pasien Hipertensi di RSUD Syekh Yusuf Gowa yang berfluktuasi dari tahun ke tahun dan cenderung meningkat, maka masalah Hipertensi perlu mendapat perhatian dan penatalaksanaan yang menyeluruh dan sungguhsungguh. Hal ini yang mendorong penulis untuk melakukan penelitian mengenai "Upaya Pemeliharaan Tekanan Darah bagi Pasien Hipertensi di RSUD Syeh Yusuf Sungguminasa Kabupaten Gowa"

\section{B. Rumusan masalah}

1. Apakah pasien hipertensi mengontrol tekanan darah secara teratur?

2. Apakah pasien hipertensi mengikuti pola diet hipertensi dalam kehidupan seharihari?

3. Apakah pasien hipertensi minum obat hipertensi secara teratur sesuai aturan?.

4. Apakah pasien hipertensi melakukan olah raga secara teratur?

\section{Tujuan Penelitian}

a. Untuk mengetahui pasien mengontrol tekenan darah secara teratur.

b. Untuk mengetahui pasien menjalankan deit hipertensi.

c. Untuk mengetahui pasien berobat secara teratur.

d. Untuk mengetahui pasien dalam berolahraga secara teratur.

\section{Manfaat Penelitian}

1. Pasien hipertensi/keluarganya dapat meningkatkan kesadaran dan pengetahuannya dalam upaya pemeliharaan tekanan darah agar tetap dalam keadaan terkontrol.

2. Sebagai bahan bacaan bagi masyarakat tentang hipertensi dan permasalahannya, menjaga dan memelihara kesehatan jauh lebih dari baik dari pada berobat setelah jatuh sakit. 


\section{METODE PENELITIAN}

\section{A. DesainPenelitian}

Desainpenelitian yang digunakan adalah deskriptif analisis, yang memberikan suatu gambaran tentang upaya pasien dalam mengontrol tekanan darah pada pasien hipertensi di RSUD Syeh Yusuf Kabupaten Gowa

\section{B. Waktu dan Tempat Penelitian}

1. Waktu

Penelitian ini dilaksanakan pada tanggal

27 Mei sampai dengan 27 Juni 2013

2.Tempat Penelitian

Penelitian ini dilaksanakan di RSUD Syekh

Yusuf Kab.Gowa

\section{PopulasidanSampel}

1. Populasi

Populasi dalam penelitian ini adalah seluruh pasien hipertensi yang di Rawat Inap RSUD SyekhYusufKab.Gowa

2.Sampel

a.BesarsampelJumlah sampel ditentukan dengan menggunakan rumus:

$$
\mathrm{n}=\frac{\mathrm{N} \cdot \mathrm{z}^{2} \mathrm{p} \cdot \mathrm{q}}{\mathrm{d}(\mathrm{N}-1)+\mathrm{z} \cdot \mathrm{p} \cdot \mathrm{q}}
$$

Keterangan :

$\mathrm{n}=$ besar sampel

$\mathrm{N}=$ jumlahpopulasi

$\mathrm{d}=$ toleransi kesalahan yang dipilih $(\mathrm{d}=0,05)$

$\mathrm{z}=$ Hargakurva normal yang tergantung dar iharga alfa $(z=1,96)$

$\mathrm{p}=$ estimate or proporsi populasi (jika tidak diketahui dianggap 50\%)

$\mathrm{q}=1-\mathrm{p}(100 \%-\mathrm{p})$ maka $(100 \%-50 \%)=$ $50 \%=0,5$

Berdasarkan rumus di atas, maka jumlah sampel sebanyak:

233.1,96 2 X $0,5 \times 0,5$

$\mathrm{n}=\overline{0,05(233-1)+1,96 \times 0,5 \times 0,5}$

$233.3,84$

$\mathrm{n}=$

\section{E. InstrumenPenelitian}

Instrumen yang digunakan adalah kuesioner dalam bentuk chek list dengan menggunakan skala Guttman dengan pilihan jawabanya ya dan tidak.

$$
\begin{aligned}
& =\frac{894,72}{11,6+1,96} \\
& =\frac{894,72}{13,56} \\
& =65 \text { sampel }
\end{aligned}
$$$$
0,05(232)+1,96
$$

Jadi jumlah sampel sebanyak 65 orang

b. Tekniksampel

Teknik pengambilan sampel merupakan proses seleksi sampel yang digunakan dalam penelitian dari populasi yang ada. Adapun teknik yang digunakan yaitu teknik Purposive sampling dimana pengambilan sampel di lakukan di RSUD SyekhYusufKab. Gowa sebagai tempat pelaksaan penelitian

c. Kriteria Inklusi dan eksklusi

1) KriteriaInklusi:

a) Pasien hipertensi yang di Rawat Inap di RSUD Syekh Yusuf Kab.Gowa pada saat penelitian

b) Bersedia mengisi kuesioner

c) Pasien bisa membaca dan menulis

2) KriteriaEksklusi:

a) Pasien hipertensi yang di Rawat Inap di RSUD Syekh Yusuf Kab.Gowa

b) Tidak bersedia untuk diteliti.

c) Pasien tidak dapat membaca

D. Pengumpulan Data danAnalisis Data

1. Pengumpulan Data

Pengumpulan data dilakukan secara primer melalui observasi yang dilakukan oleh peneliti menggunakan kuisioner yang telah disediakan.

2. Analisis Data

Data yang didapatkan dianalisis secara manual dengan menggunakan rumus :

$\mathrm{P}=\frac{f}{N} \mathrm{x} 100 \%$

Keterangan :

$\mathrm{P}$ : Persentase

f : Skor yang diperoleh responden

$\mathrm{N}$ : Jumlah soal

\section{F. TeknikPengambilan Data}

Ada beberapa kegiatan yang dilakukan peneliti dalam pengolahan data yaitu: 1. Editing 
Setelah data terkumpul maka akan dilakukan editing atau penyuntingan data

2. Koding

Dilakukan untuk memudah

kanpengolahan data, yaitu dengan

melakukan pengkodean pada daftar

pertanyaan untuk setiap jawaban responden.

3. Tabulasi

Setelah dilakukan pengkodean kemudian data dimasukkan kedalam table dan diolah dengan menggunakan SPSS

untukmengetahui distribusi frekuensinya.

\section{G. AlurPenelitian}

Alur penelitian yang dilakukan yaitu:

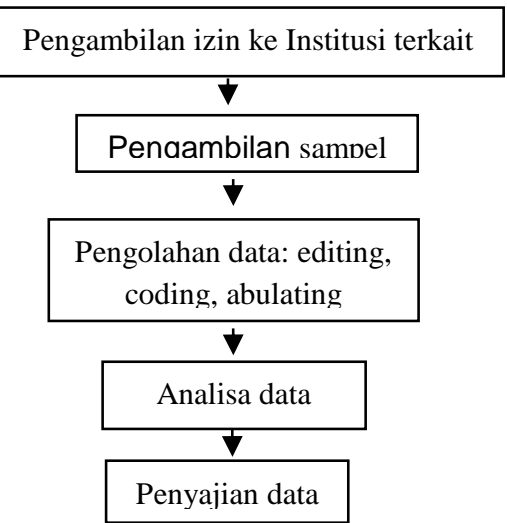

\section{H. EtikaPenelitian}

Etika penelitian keperawatan merupakan masalah yang sangat penting dalam penelitian, mengingat penelitian berhubungan langsung dengan manusia. Masalah etika yang harus diperhatikan yaitu:

1. Informed Consent

Informed consent diberikan sebelum melakukan penelitian yang berupa lembar persetujuan untuk menjadi responden.

2. Anonimity (TanpaNama)

Anonimity berartitidak perlu mencantumkan nama pada lembar pengumpulan data (kuesioner). Penelitihanya menuliskan kode pada lembar pengumpulan data.

3. Comfidentiality (Kerahasiaan)

Kerahasiaan informasi responden dijamin oleh peneliti dan hanya data tertentu yang akan dilaporkan dalam hasil penelitian.

\section{HASIL PENELITIAN}

\section{A. Deskripsi Hasil Penelitian}

Hasil penelitian dikelompokkan menjadi dua yaitu karakteristik responden dan analisa univariat. Hasil analisis di sajikan dalam bentuk tabel yang dilengkapi dengan penjelasan sebagai berikut:

1. Karakteristik responden

a. Umur

Tabel 5.1 Distribusi responden berdasarkan kelompok Umur

\begin{tabular}{|c|c|c|c|}
\hline No & Umur & $\mathrm{f}$ & $\%$ \\
\hline 1 & $25-44$ & 22 & 33,9 \\
\hline 2 & $45-64$ & 32 & 49,2 \\
\hline 3 & $>\quad 65$ & 11 & 16,9 \\
\hline & Total & 65 & 100 \\
\hline
\end{tabular}

Tabel 5.1 menunjukkan bahwa umur pasien hipertensi terbanyak berada pada kategori umur antara 45 64 tahun yaitu $32(49,2 \%)$, sedangkan yang paling sedikit adalah memiliki umur > 65 tahun yaitu $11(16,9 \%)$, selebihnya kategori yang memiliki umur 25-44 Tahun yaitu 22 orang. 


\section{b. Pendidikan}

Tabel 5.2 Distribusi responden berdasarkan tingkat Pendidikan

\begin{tabular}{|c|c|c|c|}
\hline No & Pendidikan & f & $\%$ \\
\hline 1 & SD & 26 & 40 \\
2 & SMP & 17 & 26,1 \\
3 & SMA & 18 & 27,6 \\
4 & S1 & 4 & 6,1 \\
\hline & Total & 65 & 100 \\
\hline
\end{tabular}

Tabel 5.2 menunjukkan bahwa tingkat pendidikan pasien hipertensi tertinggi berada pada kategori SD sebanyak 26 orang (40\%), sedangkan c. Pekerjaan

\begin{tabular}{|c|c|c|c|}
\hline No & Pekerjaan & f & $\%$ \\
\hline 1 & I.R.T & 33 & 50,8 \\
2 & Wiraswasta & 12 & 18,4 \\
3 & PNS & 4 & 6,1 \\
4 & Petani & 16 & 24,7 \\
\hline & Total & 65 & 100 \\
\hline
\end{tabular}

Tabel 5.3 menunjukkan bahwa dari 65 responden, paling banyak memiliki pekerjaan IRT terdapat 33 orang $(50,8 \%)$ dan paling sedikit pendidikan paling rendah yakni $\mathrm{S} 1$ hanya terdapat $4(6,1 \%)$ responden, selebihnya memiliki pendidikan SMP, dan SMA.

2. Analisis Karakteristik variabel responden

a. Mengontrol Tekanan Daraah

Tabel 5.4. Upaya responden dalam mengontrol tekanan darah secara teratur

\begin{tabular}{|c|c|c|c|}
\hline NO & Upaya & $\mathrm{f}$ & $\%$ \\
\hline 1 & Mengontrol & 6 & 9,2 \\
\hline 2 & Tidakmengontol & 59 & 90,8 \\
\hline & Total & 65 & 100 \\
\hline
\end{tabular}

Table 5.4 menunjukkan bahwa dari 65 responden, yang tidak mengontrol tekanan darah memiliki pekerjaan PNS hanya terdapat 4 orang $(6,1 \%)$, selebihnya memiliki pekerjaan wiraswasta dan petani.

b. Pengetahuan Pasien Hipertensi Tentang Diet Hipertensi

Tabel 5.5. Distribusi responden tentang Diet pada pasien Hipertensi

\begin{tabular}{|c|c|c|c|}
\hline No & Pengetahuan & $\mathrm{f}$ & $\%$ \\
\hline 1 & Baik & 8 & 12,3 \\
2 & Kurang & 57 & 87,7 \\
& & & 100 \\
\hline
\end{tabular}


Tabel 5.5 menunjukkan bahwa dari 65 responden, yang memiliki pengetahuan yang masih kurang tentang diet hipertensi diantaranya 57orang $(87,7 \%)$, sedangkan yang memiliki pengetahuan baik 8 orang $(12,3 \%)$.

c. Pengetahuan Pasien Hipertensi tentang Berolahraga Secaraa Teratur Tabel 5.6. Distribusi Responden Berolahraga Secara Teratur

\begin{tabular}{|c|c|c|c|}
\hline No & Pengetahuan & $\mathrm{f}$ & $\%$ \\
\hline 1 & Baik & 6 & 9,2 \\
2 & Kurang & 59 & 90,8 \\
\hline & Total & 65 & 100 \\
\hline
\end{tabular}

Tabel 5.6 menunjukkan bahwa dari 65 responden, yang memiliki pengetahuan yang masih kurang tentang berolahraga diantaranya 59

orang $(90,8 \%)$, sedangkan yang memiliki pengetahuan baik 6 orang $(9,2 \%)$.

d. Keteraturan Pasien Hipertensi Berobat

Tabel 5.7. Distribusi Responden Dalam Upaya Keteraturan Berobat

\begin{tabular}{|c|c|c|c|}
\hline No & $\begin{array}{c}\text { Keteraturan } \\
\text { berobat }\end{array}$ & $\mathrm{f}$ & $\%$ \\
\hline 1 & $\begin{array}{c}\text { Teratur } \\
\text { Tidak teratur }\end{array}$ & 4 & 6,1 \\
2 & Total & 65 & 93,9 \\
\hline & \multicolumn{2}{c}{} \\
\hline
\end{tabular}

$$
\text { Pada Tabel } \quad 5.7
$$

menunjukkan bahwa dari 65 responden, yang berobat secara tidak teratur diantaranya 61 orang

\section{B. Pembahasan}

Setelah dilakukan pengumpulan, pengolahan, dan penyajian data, maka peneliti akan melakukan pembahasan hasil penelitian yang dikaitkan dengan berbagai referensi yang ada. Penelitian ini bertujuan untuk mendapatkan gambaran upaya pasien dalam mengontrol tekanan darah pada pasien hipertensi di RSUD Syekh Yusuf Kabupaten Gowa.

1. Mengontrol Tekanan Darah

Hipertensi tidak akan muncul begitu saja. Naik turunnya tekanan darah, biasanya merupakan akumulasi dari sikap hidup yang tidak sehat dan kurun waktu lama. Semua kebiasaan -kebiasaan yang buruk dalam kehidupan dan pola makan yang tidak sehat akan menambah daftar buruk yang mamicu terjadinya hipertensi. Sebagai langkah yang harus dilakukan yaitu dengan menjalankan pola hidup yang sehat adalah makan makanan yang mengandung kalori dan kebutuhan
$(93,9 \%)$, sedangkan berobat secara teratur 4 orang $(6,1 \%)$.

nutrisi sesuai dengan kebutuhan yang diperlukan. (Wulandari, 2011)

Pola makan sehat, bersama dengan berolahraga teratur rmemiliki kekuatan untuk membantu mencegah penyakit jantung dan hipertensi. (Casey dan Benson, 2006)

Dari hasil penelitian dilakukan di RSUD Syekh Yusuf pada tanggal 27 Mei sampai 27 Juni 2013 menunjukkan bahwa dari 65 responden, yang tidak mengontrol tekanan darah diantaranya 59 orang (90,8\%) sedangkan yang mengontrol tekanan darahnya 6 orang $(9,2 \%)$. Hal ini menunjukkan bahwa pasien yang mengontrol tekanan darahnya masih kurang. Ini bisa dipengaruhi oleh umur, jenis pendidikan, dan tingkat pekerjaan. Di lihat dari umur pasien yang paling tinggi mengalami hipertensi umur 45 - 64 tahun sebanyak 32 orang $(49,2 \%)$, dan dari tingkat pendidikan yang paling dominan yaitu SD sebanyak 26 orang $(40 \%)$ dan paling rendah S1 sebanyak 4 orang $(6,1)$. Jenis pekerjaan 
yang paling mendominasi yaitu I.R.T sebanyak 33 orang $(50,8 \%)$ dan Petani sebanyak 16 orang $(24,7 \%)$. Kurangnya pasien hipertensi yang berupaya mengontrol tekanan darah dapat menyebabkan masih tingginya angka hipertensi dan tingginya angka kejadian penyakit stroke yang merupakan komplikasi dari penyakit hipertensi.

Menurut Wulandari (2011), mengatakan bahwa hipertensi dapat menyerang hampir semua golongan masyarakat di seluruh dunia. Jumlah yang menderita hipertensi terus bertambah dari tahun ketahun. Dari data penelitian terakhir bahwa $15 \%$ dari 230 juta penduduk Indonesia, berarti hampir 35 juta penduduk Indonesia terkena hipertensi.

2. Diet Hipertensi (Diet Rendah Garam)

Diet hipertensi ini dapat dilakukan dengan mengurangi asupan garam yang masuk kedalam tubuh dengan menggunakan ukuran sekitar satu sendok teh garam perhari dan memperbanyak komsumsi serat dapat memperlancar buang air besar dan mengurangi asupan nutrisi. Diet ini juga dilakukan dengan menghentikan kebiasaan buruk seperti minum minuman alkohol dan kopi yang dapat memacu detak jantung. Selain itu, memperbanyak asupan kalium dapat membantu kelebihan natrium. (Wulandari, 2011)

Diet DASH dapat menurunkan tekanan darah dan dapat menghilangkan kebutuhan terhadap pengobatan. Diet ini dapat memungkinkan untuk mengurangi dosis atau jumlah obat yang di komsumsi. Diet DASH juga mendorong komsumsi biji-bijian. Manfaat diet DASH akan menjadi lebih baik lagi bila mengurangi sodium dalam makanan. (Casey dan Benson, 2006)

Untuk mencegah asupan sodium yang berlebihan sebagai penggantinya tersedia garam diet. Garam diet adalah garam yang tidak mengandung sodium, tetapi mengandung mineral lain, umumnya, berupa kalium klorida (KCL). Diet rendah garam dengan membatasi asupan garam sebanyak $1.500 \mathrm{mg} / \mathrm{hari}$. (Lingga, 2012)

Dari hasil penelitian terhadap 65 responden yang dilakukan diRSUD Syekh Yusuf Kabupaten Gowa diperoleh data bahwa gambaran upaya pasien dalam mengontrol tekanan darah pada pasien hipertensi dengan diet hipertensi masih kurang atau sekitar 57 orang $(87,7 \%)$ dan yang melakukan diet hipertensi yang baik sebanyak 8 orang $(12,3 \%)$.

Dari data penelitian yang di dapat menunjukkan bahwa pengetahuan pasien tentang diet hipertensi masih kurang tiu di karenakan pasien hipertensi tidak mengetahui makanan apa yang harus dihindari misalnya mengurangi mengonsumsi makan yang terlalu banyak mengandung garam seprti telur asin, kepitng, kerang dan daging. Semuanya itu bisa meningkatkan tekanan darah. Hal ini bisa dipengaruhi dari tingkat pengetahuan pasien yang dimana di dominasi tingkat pendidikan SD yaitu sebanyak 26 orang (40\%), dantingkat SMP sebanyak 17 orang $(26,1 \%)$. Dan dapatjuga di lihat dari jenis pekerjaan yang kebanyak I.R.T dan Petani.

Jika dibandingkan dengan Negara lain di Asia, Jepang menduduki ranking pertama sebagai Negara dengan presentase menderita hipertensi terbesar yang banyak menyukai makanan yang asin.

3. Berolahraga secara teratur

Kurangnya aktifitas fisik atau berolahraga merupakan salah satu factor utama terjadinya hipertensi, terutama bila gaya hidup pasif itu dimulai sejak usia muda. Dengan berolahraga aerobic secara teratur dan dalam takaran cukup, pasien hipertensi bisa meningkatkan kebugaran sekaligus kualitas hidupnya. Latihan berolahraga bisa pula menurunkan risiko mengalami penyakit jantung. Misalnya selama melakukan latihanlatihan aerobic yang keras, tekanan darah sistolik naik menjadi 150 -200 mmHg dari tekanan sistolik ketika beristirahat sebesar 110 $-20 \mathrm{mmHg}$. Sebaliknya segera satelah latihan aerobic selesai, tekanan darah akan turun sampai di bawah normal dan berlangsung selama 30 - 120 menit. Penurunan ini terjadi karena pembuluh darah mengalami pelebaran dan relaksasi. Latihan berolahraga bias menurunkan tekanan darah kerena latihan ini dapat merilekskan pembuluh - pembuluh darah. Lama-kelamaan, latihan berolahraga dapat melemaskan pembuluh-pembuluh darah sehingga tekanan darah menurun. Latihan berolahraga juga dapat menyebabkan aktifitas saraf, reseptor hormone dan produksi hormonehormon tertentu menurun. (Wulandari, 2011)

Dari hasil penelitian terhadap 65 responden yang dilakukandi RSUD Syekh Yusuf diperoleh data bahwa gambaran upaya pasien dalam mengontrol tekanan darah pada padap pasien hipertensi dengan berolahraga sangat kurang atau sekitar 59 orang $(90,8 \%)$ dan yang tidak berolahraga sekitar 6 orang $(9,2 \%)$,

Dari data menunjukkan masih kurangnya pengetahuan tentang manfaat dari berolahraga. 
Dengan melakukan olahraga secara teratur bisa menurunkan tekanan darah tinggi. Jika sudah dinyatakan positif menderita tekanan darah tinggi, yang harus dilakukan yaitu dengan berolahraga ringan. Olahraga dilakukan selama 30 hingga 45 menit sehari. Kurangnya pasien hipertensi yang berupaya mengontrol tekanan darah dengan berolahraga menyebabkan masih tingginya angka hipertensi dan tingginya angka kejadian penyakit stroke yang merupakan komplikasi dari penyakit hipertensi.

\section{Keteraturan Berobat}

Pengobatan untuk mengatasi hipertensi adalah pengobatan yang menggunakan obatobatan kimia. Bila pengobatan obat-obat kimia ini ditangani oleh dokter untuk menjalani serangkaian proses pemeriksaan. Tujuannya untuk mendiagnosis tingkat keparahan hipertensinya dan menentukan jenis obat yang paling tepat diberikan. (Wulandari, 2011).

Tujuan tiap program penanganan bagi setiap pasien adalah mencegah terjadinya amorbiditas dan mortalitas penyerta dengan mencapai dan mempertahankan tekanan darah dibawah 140/90 mmHg. Efektifitas setiap program ditentukan oleh derajat hipertensi, komplikasi, biaya perawatan, dan kualitas hidup sehubungan dengan terapi. Obat-obatan yang digunakan meliputi penyekat betaadrenergik, penyekat alfa-reseptor, antagonis kalsium (penyekat saluran kalsium), diuretik seperti furosemid yang berfungsi untuk menurunkan tekanan darah, serta inhibitorenzim yang mengkonversi angiotensin (ACE) seperti captopril yang merupakan obat antihipertensi. (Smeltzer,2004)

Obat antihipertensi golongan diuretic bekerja dengan cara membuang kelebihan air dan natrium melalui pengeluaran urine. Berkurangnya air dalam darah mengakibatkan volume darah menurun sehingga pekerjaan jantung ringan. Pemakai obat jenis ini mengalami banyak buang air kecil. Golongan obat ini merupakan pilihan pertama untuk pengoobatan hipertensi. Penggunaan diuretic dalam dosis tinggi dapat memicu encok dan diabetes. Selain itu, dapat menurunkan potassium dalam darah dan meningkatkan kadar kolesterol atau lemak. Sedangkan golongan Beta-Blocker bekerja dengan cara memperlambat kerja jantung dan menurunkan tekanan darah. (Widharto, 2007).

Dari hasil penelitian terhadap 65 responden yang dilakukan diperoleh data bahwa gambaran upaya pasien dalam mengontrol tekanan darah pada pasien hipertensi dengan berobat secara teratur masih kurang atau sekitar 61 orang $(93,9 \%)$ dan yang berobat secara teratur sebanyak 4 orang $(6,15$ $\%)$.

Dari hasil penelitian menunjukkan bahwa masih tingginya pasien hipertensi yang tidak memeriksakan kesehatannya sehingga banyak masyarakat yang mengalami hipertensi. Selain itu, pasien hipertensi juga sering menghentikan pengobatan tanpa intruksi dari dokter ini semua yang bisa menyebabkan serangan jantung, stroke, gagal jantung, penyakit ginjal kronis,. Tetapi masih ada sekitar $6,1 \%$ yang berobat secara teratur itu di karenakan pasien hipertensi sering mengontrol tekanan darahnya ke puskesmas atau rumah sakit apabila tekanan darahnya meningkat.

\section{PENUTUP}

\section{A. Kesimpulan}

Berdasarkan hasil analisis data yang di dapatkan sesuai dengan tujuan penelitian yaitu gambaran upaya pasien dalam mengontrol tekanan darah pada pasien hipertensi di RSUD Syekh Yusuf Kabupaten Gowa maka dapat disimpulkan sebagai berikut:

1. Upaya pasien dalam mengontrol tekanan darah masih kurang. Hal ini menunjukkan bahwa dari 65 responden, yang tidak mengontrol tekanan darahnya 59 orang $(90,8 \%)$, sedangkan yang mengontrol tekanan darahnya 6 orang $(9,2 \%)$. Hal ini berarti masih banyak yang tidak berupaya mengontrol tekanan darahnya.

2. Upaya pasien dalam mengontrol tekanan darah dengan menjalankan diet hipertensi masih kurang. Hal ini menunjukkan bahwa dari 65 responden, yang memiliki pengetahuan yang masih kurang tentang diet hipertensi diantaranya 57 orang $(87,7 \%)$, sedangkan yang memiliki pengetahuan baik 8 orang $(12,3 \%)$.

3. Upaya pasien dalam menurunkan tekanan darah dengan berolahraga masih kurang. Hal ini menunjukkan bahwa dari 65 responden, yang memiliki pengetahuan yang masih kurang tentang berolahraga diantaranya 59 orang $(90,8 \%)$, sedangkan yang memiliki pengetahuan baik 6 orang $(9,2 \%)$

4. Upaya pasien dalam mengontrol tekanan darah dengan berobat secara teratur masih kurang. Hal ini menunjukkan bahwa dari 65 responden, yang berobat secara tidak teratur diantaranya 61 orang $(93,9 \%)$, sedangkan 
yang berobat secara teratur yaitu 4 orang $(6,1 \%)$.

\section{DAFTAR PUSTAKA}

Askes. Buku Pemantauan Status Kesehatan, bagi Peserta Program pengelolaan Penyakit Kronis Diabetes Tipe 2 dan Hipertensi. PT Askes (Persero).

Ardiansyah, Muhammad (2012). Medikal Bedah Untuk Mahasiswa. Jogjakarta : Diva Perss.

Corwin, Elisabeth J. (2009). Buku Saaku Patofisiologi.EGC.Jakarta

Casey, Aggie R. N, M. Sdan Benson, Herbert, M.D (2006). Menurunkan Tekanan Darah. Bhuana. Jakarta

Hidayat,A Aziz Alimul.(2007). Riset Keperawatan dan Teknik Penulisan Ilmiah. Salemba Medika. Jakarta

Lang, Stefan Silbernagl Florian.2012. Teks \& Atlas Berwarna Patopisiologi. Penerbit Buku Kedokteran.EGC. Jakarta

Lingga, Lanny PhD.(2012).

BebasHipertensiTanpaObat.

AgroMedia.Jakarta

Mikail, Bramirus. (2011). 10 Cara MenurunkanTekananDarah.Kompas. Com. 22 Maret 2013
Kusuma, Amin Hunda Nurarif Hardhi. .2015. Aplikasi Asuhan Keperawatan Berdasarkan Diagnose Medis \& NANDA. NIC-NOC. Edisi Revisi Jilid 2.

Notoatmojo,soekidjo.(2007). IlmuKesehatanMasyarakat.RinekeCipta.Ja karta.

Price, Sylvia A. Willson, Lorraine M. (2006). Patofisiologi Konsep Klinis Proses-Proses Penyakit. EGC.Jakarta.

Reeves, Harlene J.et all. (2001). KeperawatanMedikalBedah. SalembaMedika. Jakarta

Smeltser, Susanne C. Bare, Brenda G. (2002).

Brunner \&Suddarth Buku Ajar Keperawatan Medikal Bedah. EGC. Jakarta.

Wulandari, Ari. (2011). Cara JituMengatasiHipertensi. ANDI. Yogyakarta

Widharto, dr. (2007). BahayaHipertensi. SundaKelapa. Jakarta

Wijoyo, IR. Padmianso M. (2011). RahasiaPenyembuhanHipertensiSecaraAla mi.Gramedia. Jakarta 